\title{
Single Band Notched Characteristics UWB Antenna using a Cylindrical Dielectric Resonator and U-shaped Slot
}

\author{
DEBAB Mohamed, MAHDJOUB Zoubir \\ Laboratory Electromagnetic Photonics Optronics (LEPO), Djillali liabes University of Sidi Bel Abbès, 22000 \\ Sidi Bel Abbès, Algeria \\ debab_telecoms2005@hotmail.fr,mahdjoubz@yahoo.com
}

\begin{abstract}
In this manuscript, a novel hybrid dielectric resonator antenna for ultra wideband (UWB) applications is designed, and single band notched performance is proposed. The circle radiating patch is printed on the FR4 substrate of $1.64 \mathrm{~mm}$ thickness and loss tangent $\tan \delta=0.02$, and is fed by the coplanar waveguide. The size of the UWB antenna was minimised to $50-40 \mathrm{~mm}^{2}$. The cylindrical dielectric resonator (CDR) was used to broaden the bandwidth and achieve an impedance bandwidth of more than $113 \%$, covering a frequency range of 3.3 to more than 12GHz. WIMAX band notched characteristics of the antenna to reject $(3.2-3.8 \mathrm{GHz})$ were realised by etching a $U$-shaped slot in the radiating patch. The centre notch frequency can be adjusted from 3.4 to $4.5 \mathrm{GHz}$ by changing the position of the CDR. The band notched characteristics, VSWR, and radiation patterns were studied using the CST microwave simulator and confirmed with the frequency domain ANSOFT high frequency structure simulator (HFSS).
\end{abstract}

Index Terms - Cylindrical dielectric resonator (CDR), planar monopole, band-stop function, U-shaped slot.

\section{INTRODUCTION}

Dielectric resonator antennas (DRAs) have received much attention in recent years due to their high efficiency, small size, and low metallic losses. DRAs can be excited by different feeding mechanisms with various shapes [1]. Moreover, various DRAs have been designed to focus on the bandwidth and input impedance, and can be easily adjusted by varying the antenna specifications, e.g., choosing the dielectric constant of the resonator material, dimensions, and feed mechanisms. Several researchers have proposed broadening the operation bandwidth of a DRA with the use of different configuration shapes, e.g., L-shaped, elliptical, T-shaped, and stair-shaped [2-6]. Another method using different composite DRA structures has also been analysed [7-10]. Recently, band notched DRAs have been designed to minimise interference between the ultrawide band (UWB) system and some narrowband systems, such as WIMAX and WLAN. A reconfigurable band rejection antenna has also been designed for different narrowband services operating inside 3.1-10.6 GHz [11,12]. Dual band DRAs have been designed to produce notches in the WIMAX and WLAN bands by splitting a rectilinear DR and etching some of the dielectric material [13]. Numerous techniques have been developed to create band notched functions, such as using a strip near patch [14], quarter wavelength tuning stubs [15], 
fractal tuning stubs [16], and etching slots on the radiator, e.g., rectangle [17], C-shaped [18], Ushaped [19], arc-shaped [20], Y-shaped [21],L-shaped [22],T-shaped [23], inverted S-shaped [24], Hshaped [25], and $\pi$-shaped slots [26].

In this work, we present a novel simple UWB cylindrical dielectric resonator (CDR) antenna with single band notched characteristics at $3.4 \mathrm{GHz}(3.2-3.8 \mathrm{GHz})$. The rejected frequency was realised by the dielectric resonator and etching a U-shaped slot quarter-wavelength on the circle radiation patch. In this design, tuning of the notched centre frequencies is done by changing the length of the slot and the position of the dielectric resonator. The simulation to optimize design is done using time domain analysis tools from CST Microwave Studio which provides a wide range of time domain signal that are used in UWB system. The numerical analysis of the software tools is based on Finite Difference Time Domain (FDTD). For comparison purpose, HFSS in frequency domain where the numerical analysis is based on Finite Element Method (FEM) is performed. The proposed antenna achieves an impedance bandwidth from 3.3 to over $12 \mathrm{GHz}$ with a return loss $<-10 \mathrm{~dB}$ and presents the decrement gain and efficiency radiation at approximately $3.4 \mathrm{GHz}$. The effect of the geometry of the antenna and design principle with frequency band notch characteristics are simulated with the time domain CST microwave simulator (MWS) in Section 2. The radiation pattern and simulation results of return loss with two simulators using CST and HFSS software are presented in Section 3. Concluding remarks are presented in Section 4.

\section{ANTENNA DESIGN}

The geometry of the proposed antenna is shown in Fig. 1. The antenna was fabricated on an FR4 microwave substrate with relative permittivity $\varepsilon_{\mathrm{rS}}=4.4$, dielectric loss tangent of 0.02 and thickness $\mathrm{h}=1.64 \mathrm{~mm}$. The CDR is made of DUPONT 943 material with a dielectric permittivity of 7.4 and a loss tangent of 0.002. The dimensions of the CDR are $\mathrm{D}_{\mathrm{cy}}=14 \mathrm{~mm}, \mathrm{H}_{\mathrm{cy}}=6 \mathrm{~mm}$. The CDR is excited by a circle patch with diameter, $\mathrm{a}_{\mathrm{c}}$, of $6 \mathrm{~mm}$ fed by the $50 \Omega \mathrm{CPW}$ with a signal strip width, $\mathrm{W}_{1}$, of $2 \mathrm{~mm}$ and a gap distance, $\mathrm{g}$, of $0.3 \mathrm{~mm}$. A U-shaped slot with width $t_{\mathrm{s}}=0.3 \mathrm{~mm}$ is embedded on the patch. A commercial computer simulation tool CST MWS was used to design the antenna. The optimised parameters of the antenna are listed in Table 1.

TABLE 1. OPTIMISED DIMENSIONS OF THE PROPOSED ANTENNA

\begin{tabular}{|c|c|c|c|c|c|}
\hline parameter & $(\mathrm{mm})$ & parameter & $(\mathrm{mm})$ & parameter & $(\mathbf{m m})$ \\
\hline $\mathbf{W}$ & 40 & $\overline{\mathbf{L}_{\mathrm{g}}}$ & 6.4 & $\mathbf{H}_{\mathrm{cy}}$ & 6 \\
\hline $\mathbf{L}$ & 50 & $\mathbf{L}_{\text {cut1 }}$ & 4 & $\varepsilon_{\mathrm{rD}}$ & 7.4 \\
\hline $\mathbf{h}$ & 1.64 & $\mathbf{L}_{\text {cut2 }}$ & 13 & $\mathbf{L}_{\mathrm{s}}$ & 9 \\
\hline$\varepsilon_{\mathrm{rS}}$ & 4.4 & $\mathbf{a}_{\mathrm{c}}$ & 6 & $\mathbf{t}_{\mathrm{s}}$ & 0.3 \\
\hline $\mathbf{W}_{1}$ & 2 & $p_{c}=p_{c y}$ & 0.7 & & \\
\hline g & 0.3 & $D_{\text {cy }}$ & 14 & & \\
\hline
\end{tabular}




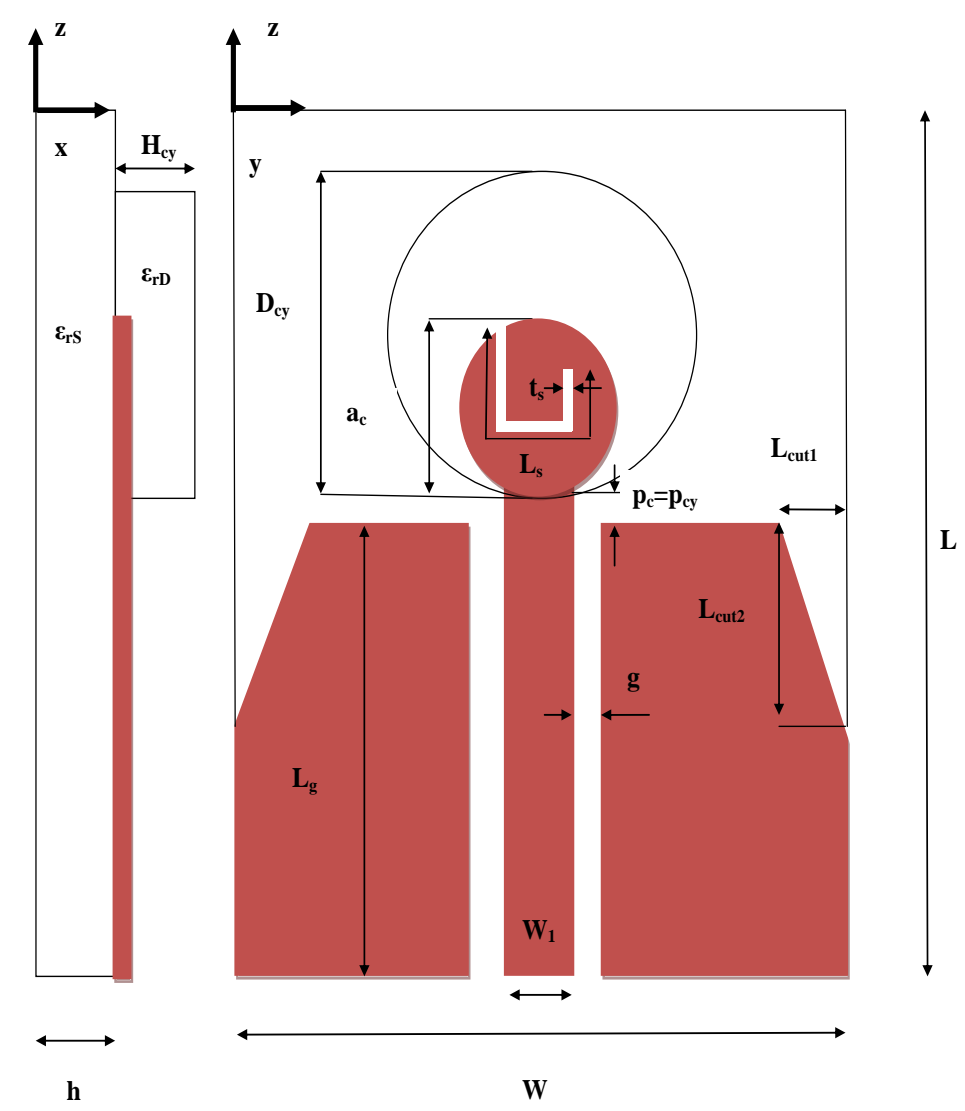

Fig.1.Geometry of the CDR antenna.

\section{A. Basic Antenna Design}

In this section, the effects of the geometric ground and gap $\mathrm{p}_{\mathrm{C}}$ between the radiation patch and ground are discussed. The parametric analysis of the proposed antenna has been carried out using the CST MWS to achieve optimal results.

The ground plane has an important role in antenna characteristics. Fig. 2 shows the simulated $\mathrm{S}_{11}$ without the U-shaped slot and CDR when $\mathrm{L}_{\text {cut }}$ is altered from 15 to $2 \mathrm{~mm}$ while the other parameters are fixed. It is clear that when $S_{11}$ is less than $-10 \mathrm{~dB}$, the lower edge frequency of the bandwidth decreases from 6.6 to $4.7 \mathrm{GHz}$, and the height edge frequency of the bandwidth also decreases. When $\mathrm{L}_{\text {cut } 1}=2 \mathrm{~mm}$, the height edge frequency of the bandwidth is $11.5 \mathrm{GHz}$ and the resulting antenna offers a broad impedance bandwidth of $84 \%$ for $S_{11}$ less than $-10 \mathrm{~dB}$ from $4.7 \mathrm{GHz}$ to $11.5 \mathrm{GHz}$ frequency band. Fig. 3 describes the simulated $S_{11}$ for different values of $L_{\text {cut2 }}$. For $L_{\text {cut2 }}=8 \mathrm{~mm}$ at $17 \mathrm{~mm}$ with another fixed parameter, the lower edge of the band is shifted to $4.6 \mathrm{GHz}$. When $\mathrm{L}_{\text {cut } 2}=13 \mathrm{~mm}$, the antenna performs with a wide bandwidth ranging from 5 to $12 \mathrm{GHz}$. 


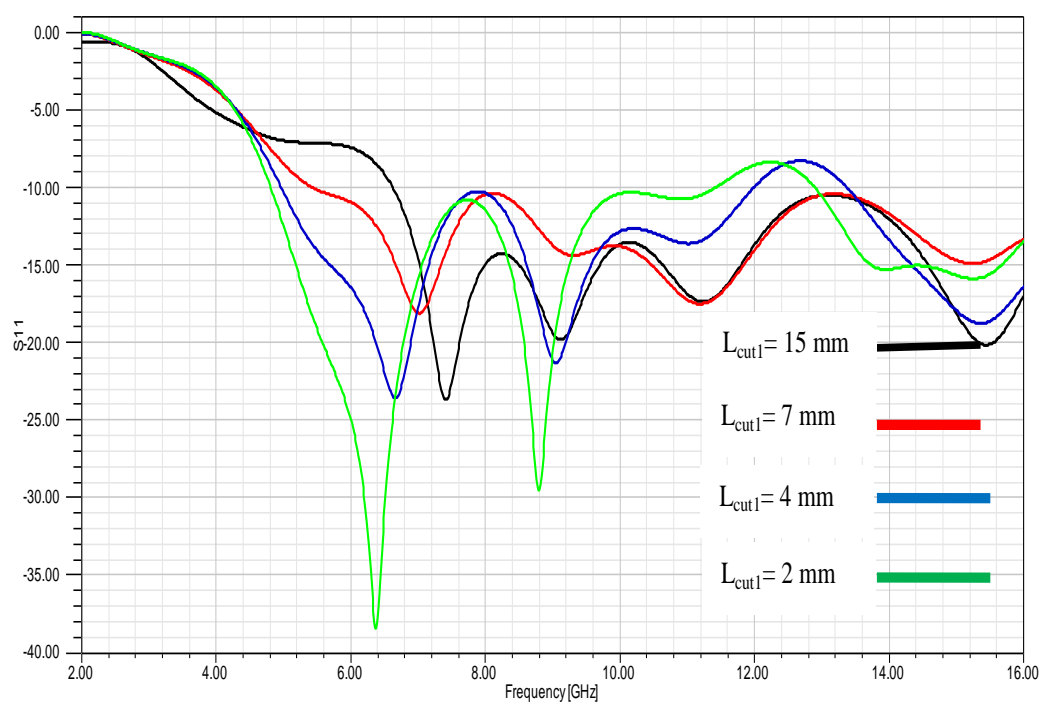

Fig.2. Simulated $\mathrm{S}_{11}$ of the basic antenna (without slot and CDR) with $\mathrm{L}_{\text {cut } 2}=13 \mathrm{~mm}$ and different values of $\mathrm{L}_{\text {cut }}$.

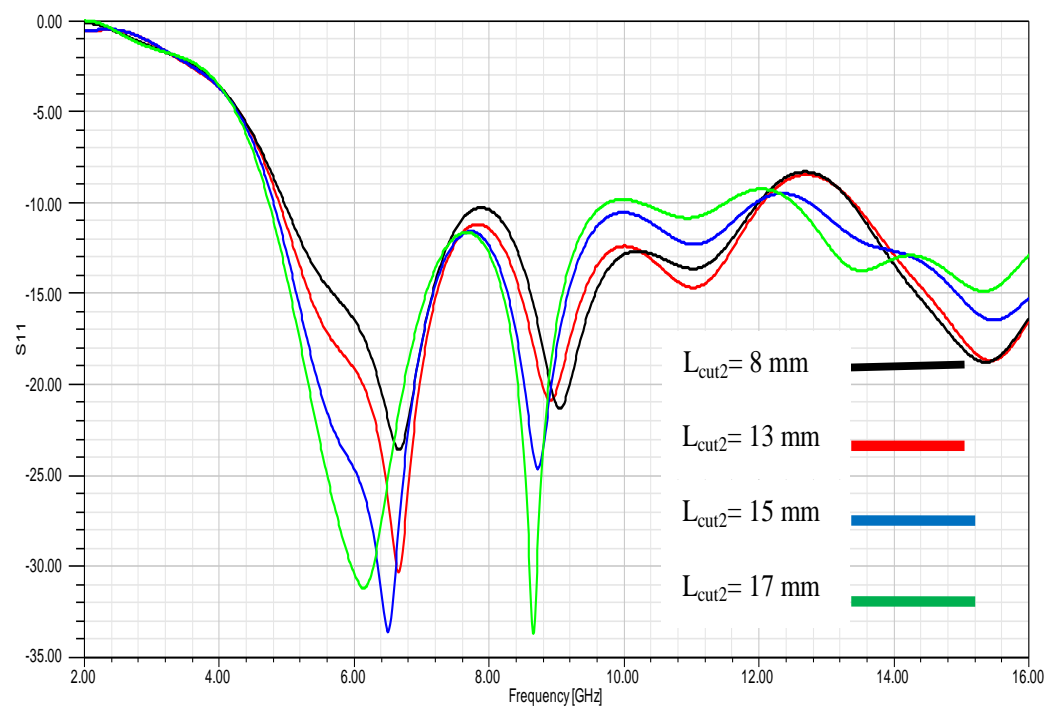

Fig.3.Simulated $\mathrm{S}_{11}$ of the basic antenna (without slot and CDR) with $\mathrm{L}_{\text {cut }}=4 \mathrm{~mm}$ and different values of $\mathrm{L}_{\text {cut2 }}$.

The variations of the return losses for different values of the gap $\mathrm{p}_{\mathrm{C}}$ between the CPW ground and radiation patch are shown in Fig. 4 with the other parameters fixed. The impedance bandwidth improved when the distance $\mathrm{p}_{\mathrm{C}}$ was decreased. When decreasing $\mathrm{p}_{\mathrm{C}}$ from 1.7 to $0.2 \mathrm{~mm}$, the height band increased from $9.4 \mathrm{GHz}$ to more than $12 \mathrm{GHz}$, and the lower frequency band was shifted from 4.2 to $5.4 \mathrm{GHz}$. This is due to the capacitive and inductive effects caused by the electromagnetic coupling between the CPW ground and the radiation patch. 


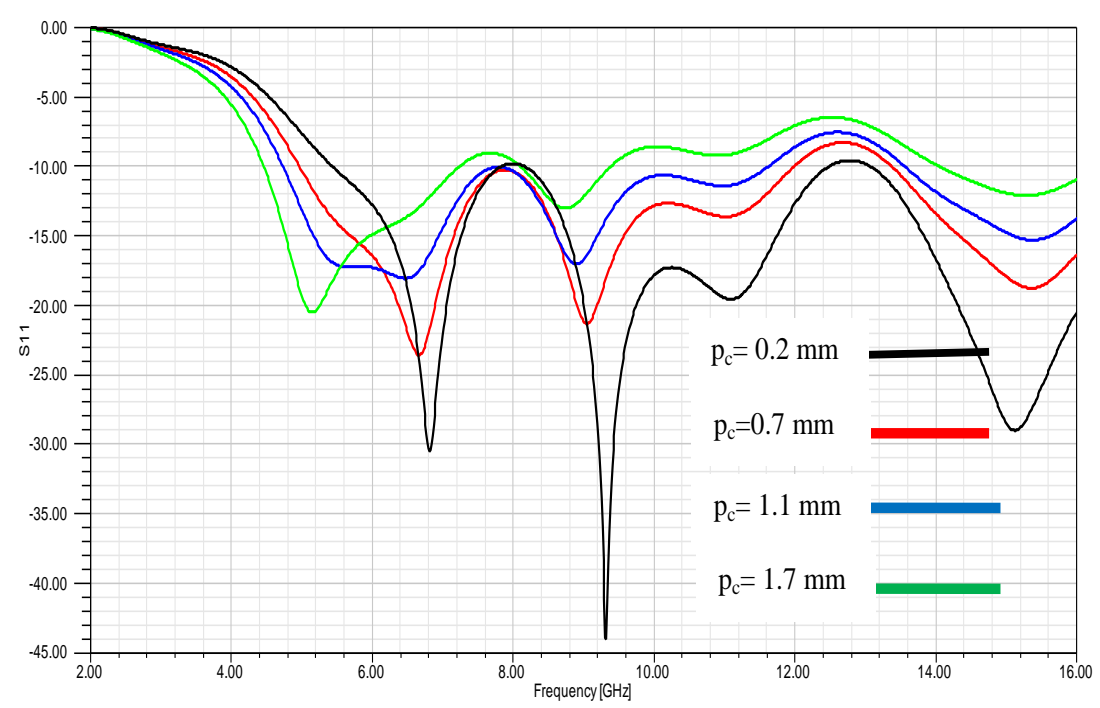

Fig.4. Simulated $S_{11}$ of the basic antenna (without slot and CDR) with different values of $\mathrm{p}_{c}$.

Fig. 5 illustrates the proposed antenna with and without the CDR. When the structure does not contain the CDR, the antenna works from 5 to $12 \mathrm{GHz}$ with $82 \%$ impedance bandwidth for reflection coefficients $<-10 \mathrm{~dB}$. When the CDR is present, the lower band shifts to $3.3 \mathrm{GHz}$ and the antenna exhibits a sharp resonance dip of $S_{11}$ is $-35 \mathrm{~dB}$ at $4.4 \mathrm{GHz}$ and the height of the band shifts to more than $12 \mathrm{GHz}$, achieving an impedance bandwidth of more than 113\%. From the simulated results, it can be concluded that the antenna with CDR provides better reflection coefficient performance to cover the WIMAX band.

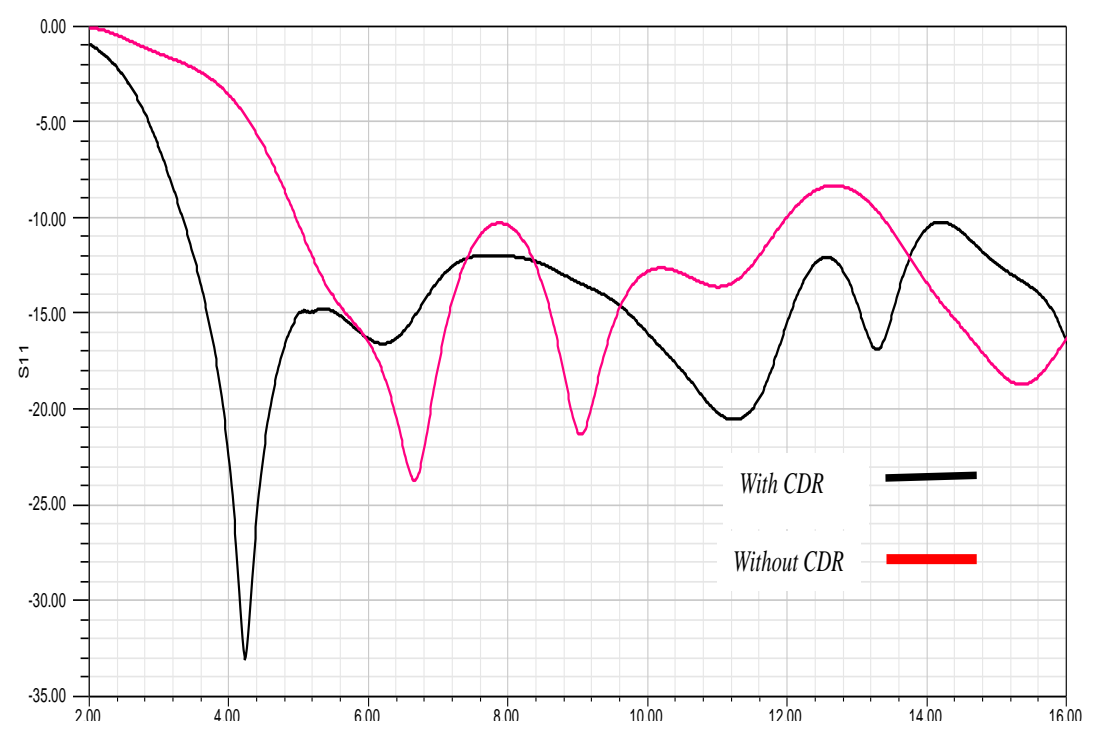

Fig.5. Simulated results of the proposed antenna with and without CDR. 


\section{B. Slot Analysis with CDR Antenna}

The U-shaped slot determines the notched band that rejects the WIMAX band, and the designed central frequency of the notch band function is to adjust the length of the slot which cuts to approximately quart wavelength. The notched frequency is given by the dimensions of the bandnotched feature as follows [27]:

$$
f_{\text {notch }}=\frac{c}{4 L_{s}} \sqrt{\frac{2}{\varepsilon_{r S}+\varepsilon_{r D}}}
$$

Where $\mathrm{L}_{\mathrm{S}}$ is the length of the $\mathrm{U}$-shaped slot, $\mathrm{c}$ is the speed of light in vacuum, and $\varepsilon_{\mathrm{rS}}$ and $\varepsilon_{\mathrm{rD}}$ are the relative permittivity of the substrate and the dielectric resonator, respectively. According to this formula, to create the cutoff frequency in the WIMAX band, the length of the slot $\mathrm{L}_{\mathrm{S}}$ will be reduced by adding a dielectric material. The $\mathrm{L}_{\mathrm{s}}$ length simulation values are compared to the theoretical predictions in Table 2.

TABLE 2. SIMULATIONS AGAINST THEORETICAL PREDICTION OF BAND-NOTCHED ANTENNA

\begin{tabular}{ccc}
\hline $\mathbf{L}_{\mathbf{s}}(\mathbf{m m})$ & Predicted(GHz) & Simulated(GHz) \\
\hline 10 & 3.08 & 3.45 \\
9 & 3.42 & 3.62 \\
8 & 3.85 & 3.94 \\
7 & 4.41 & 4.31 \\
\hline
\end{tabular}

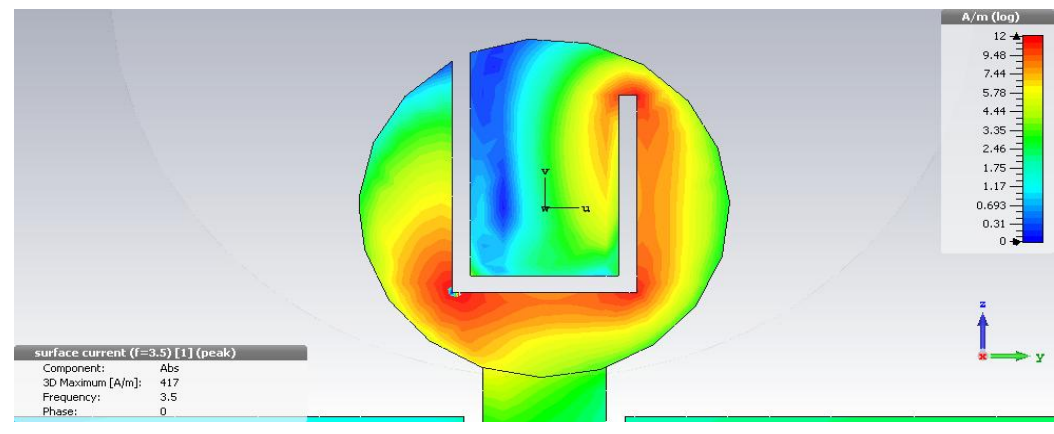

a

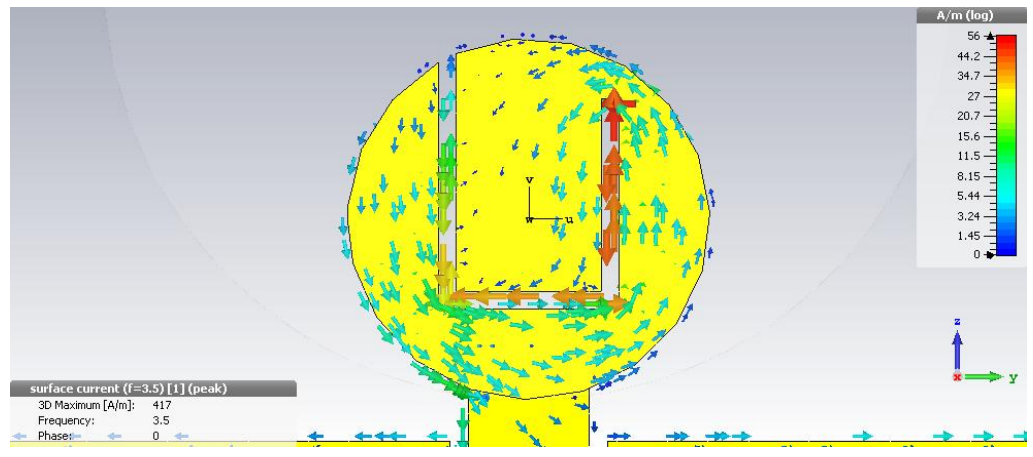

b

Fig.6.Current distribution at $3.4 \mathrm{GHz}$. 
Fig. 6 shows the current distribution at the centre notched band. The dimension of the slot $\mathrm{L}_{\mathrm{s}}=9 \mathrm{~mm}$ [determined by formula (1)] corresponds to the notched band WIMAX. It can be seen that the current is concentrated on the edge exterior of the slot (Fig. 6a), and the current paths around the straight slots are in opposite directions (Fig. 6b). When the antenna is working at the centre notched band at $3.4 \mathrm{GHz}$, the outer slot behaves as a separator.

The impact of changing the distance $\mathrm{p}_{\mathrm{cy}}$ between edge CDR and ground on the VSWR of the antenna is shown in Fig. 7. When varying $\mathrm{p}_{\mathrm{cy}}$ from 0.7 to $5.7 \mathrm{~mm}$ with fixed $\mathrm{L}_{\mathrm{S}}$, the frequency of the notched band increases from 3.47 to $4.56 \mathrm{GHz}$. The centre frequencies of the notched bands can also be adjusted by the length $L_{s}$ (Fig.8). By decreasing $L_{S}$ from 10 to $7 \mathrm{~mm}$, the notched band is shifted from 3.45 to $4.31 \mathrm{GHz}$. The optimised value of $\mathrm{L}_{\mathrm{S}}$ at which the proposed antenna rejects the whole WIMAX band (VSWR > 2) with excellent notch features is $9 \mathrm{~mm}$. The notch frequency depends on the dimensions of the U-shaped slot as well as on the CDR position.

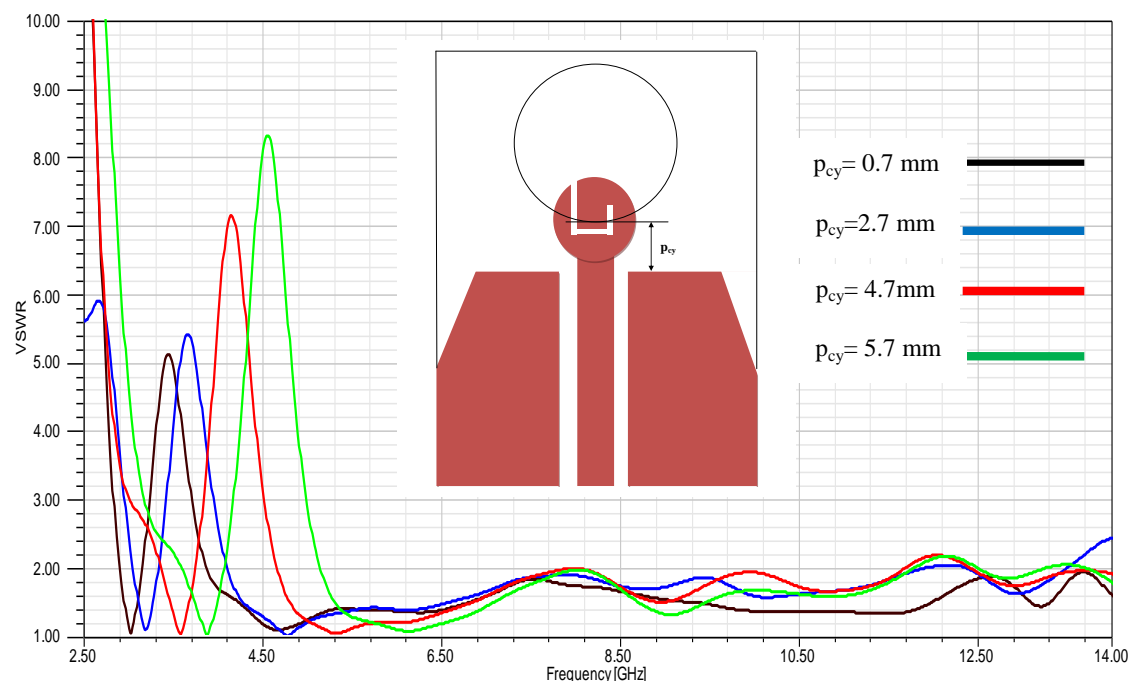

Fig.7.Influence of the position of the CDR on the VSWR of the antenna.

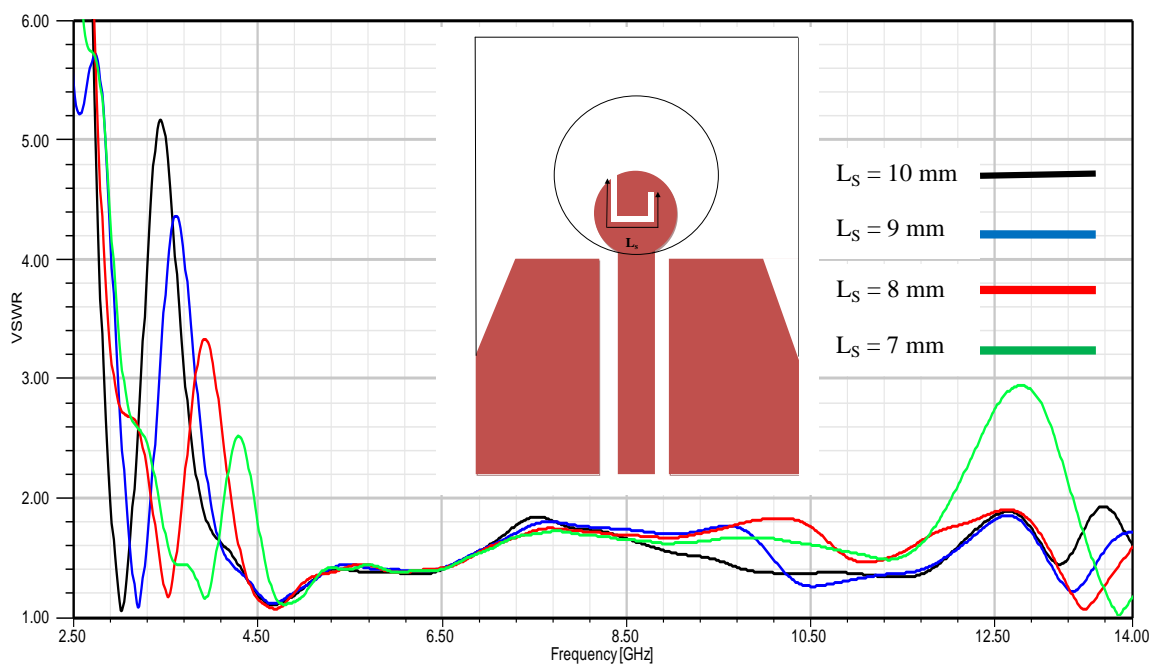

Fig.8.Influence of the length $\mathrm{L}_{\mathrm{S}}$ on the VSWR of the antenna. 
The parameter $t_{s}$ affects only the notched band and hence for simplicity, only the variation in the notched band is shown in Fig. 9. The notch bandwidth increases when $t_{s}$ increases. When $t_{s}$ is changed from 0.2 to $0.5 \mathrm{~mm}$, the filter bandwidth is varied from 0.6 to $0.7 \mathrm{GHz}$.

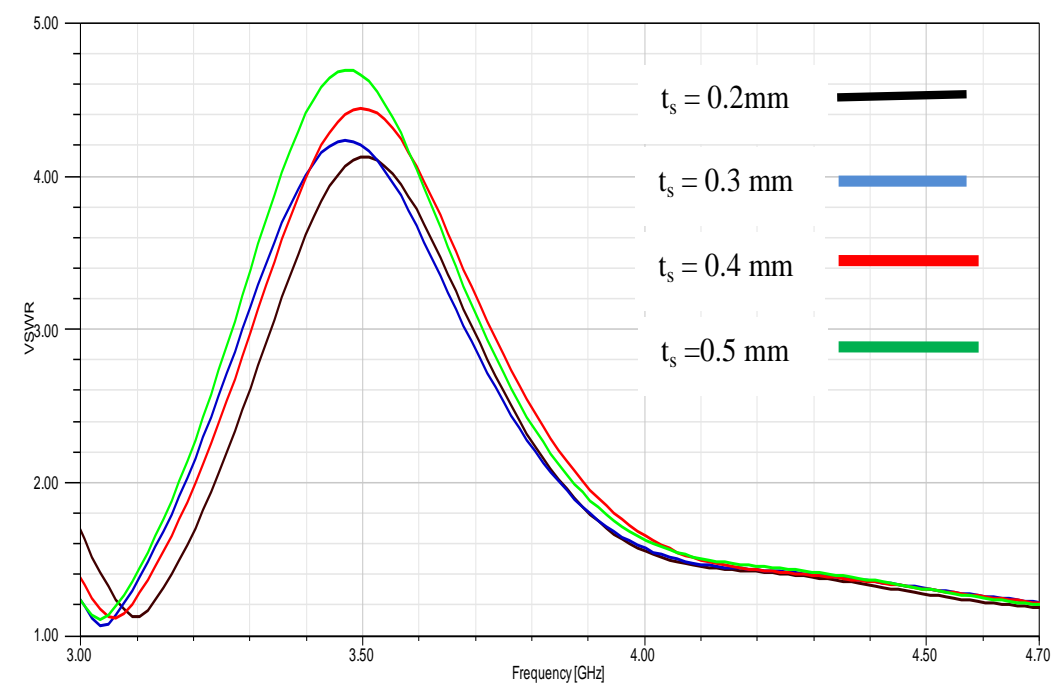

Fig.9.Effect of width $t_{S}$ on VSWR .

\section{RESULT AND DISCUSSION}

The simulated VSWR plot of the proposed antenna is shown in Fig. 10. It is clear that the band notch has been attained at the WIMAX band (VSWR > 2) and the results indicate a wide impedance bandwidth from 3.3 to more than $12 \mathrm{GHz}$. The slight difference between the simulated results of CST and HFSS is due to the different numerical techniques employed by the two softwares.

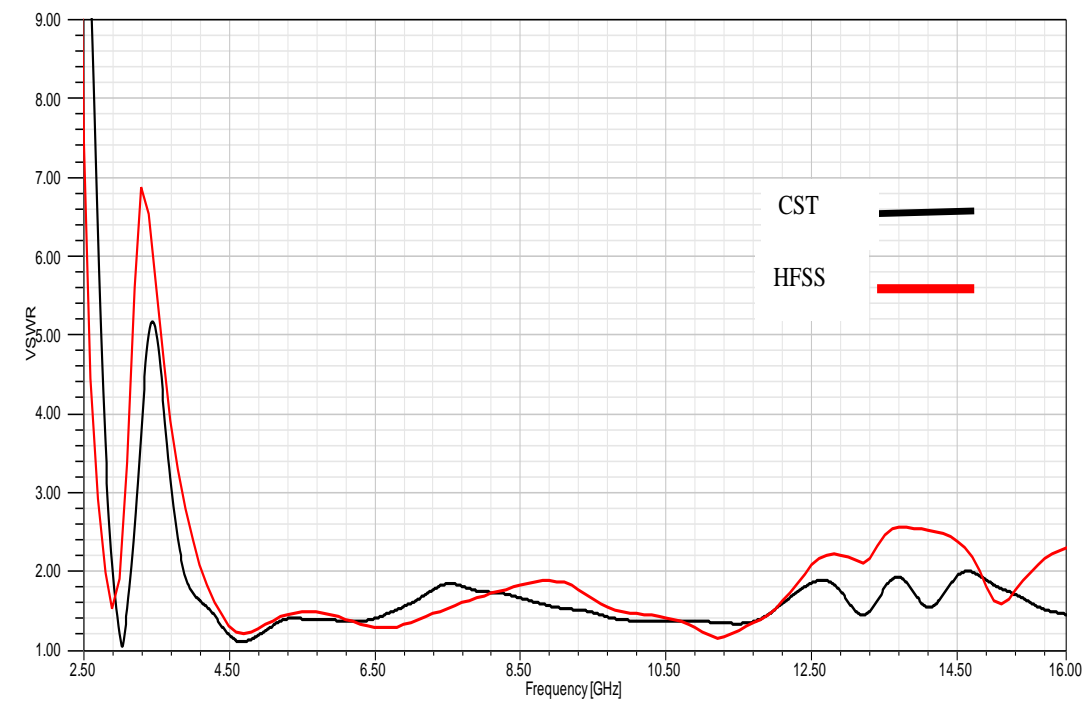

Fig.10.Simulated VSWR of the proposed antenna using CST and HFSS software. 

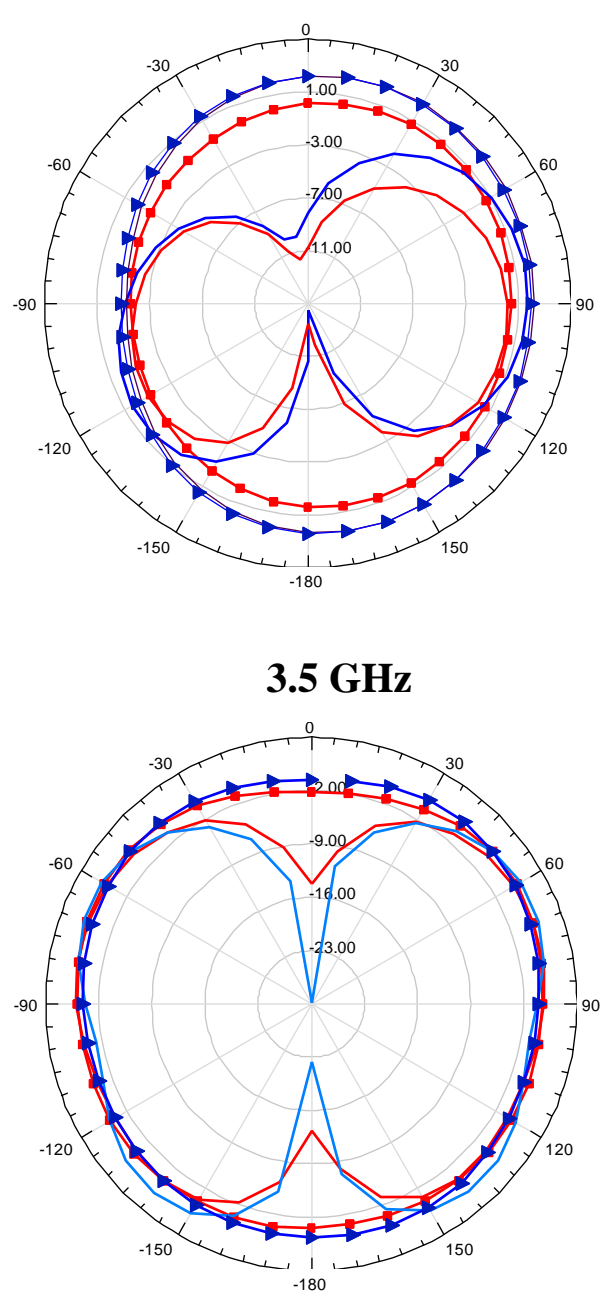

$5.5 \mathrm{GHz}$

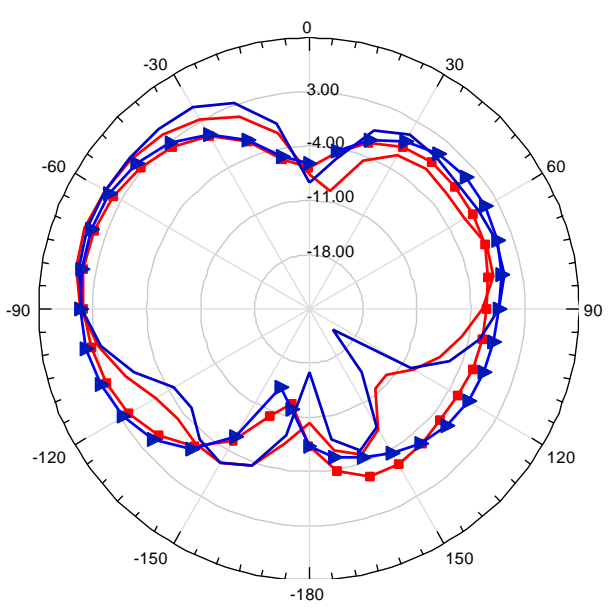

$8 \mathrm{GHz}$

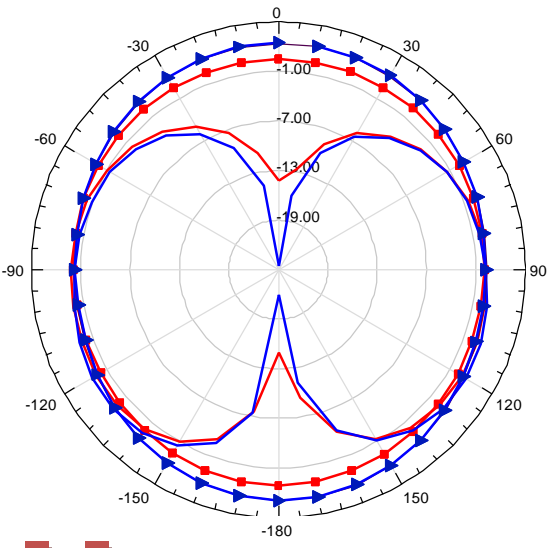

Plane H HFSS

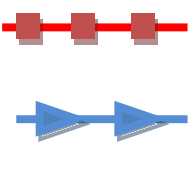

Plane H CST

Plane E HFSS

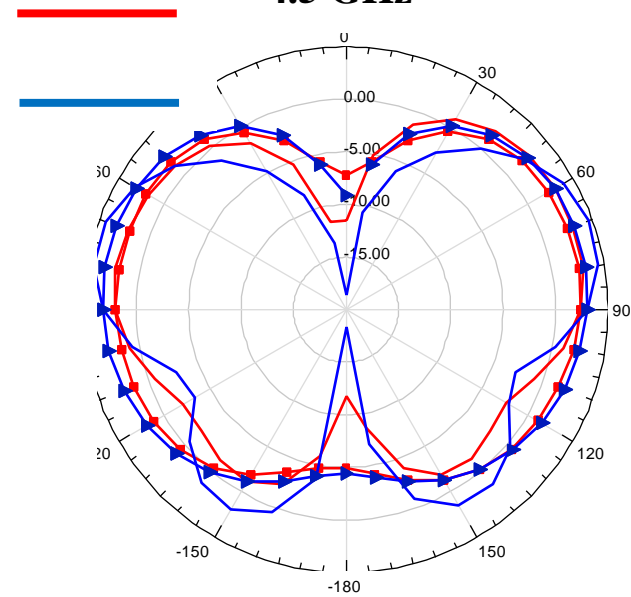

$6.5 \mathrm{GHz}$

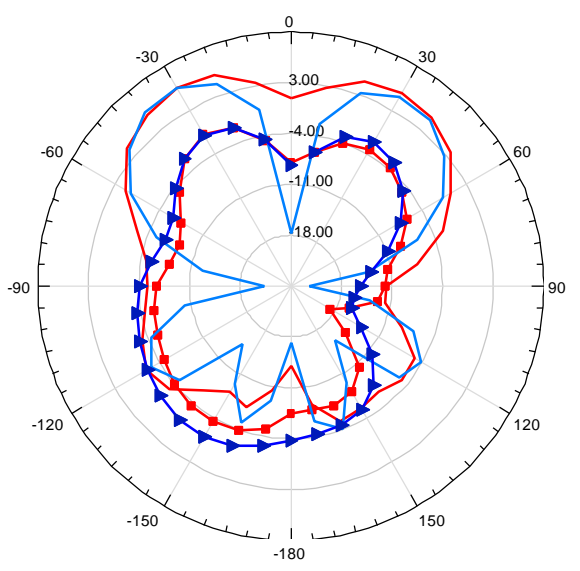

$11 \mathrm{GHz}$

Fig.11. CST and HFSS simulated directivity patterns in $\mathrm{E}(\mathrm{y}-\mathrm{z})$ and $\mathrm{H}(\mathrm{x}-\mathrm{z})$ planes for the proposed antenna at 3.5, 4.5, 5.5, $6.5,8$, and $11 \mathrm{GHz}$. 
The simulated HFSS and CST MWS E- and H-plane directivity patterns given at 3.5, 4.5, 5.5, 6.5, 8, and $11 \mathrm{GHz}$ in Fig. 11 show that the radiation pattern in the H-plane is omnidirectional, while in the E-plane, it is similar to those of a dipole at the same electric lengths. When increasing the frequency, higher order current modes are excited and the antenna exhibits directional orientation in the H-plane at $11 \mathrm{GHz}$. As can be seen in Fig. 11, good agreement is achieved between the two simulators.

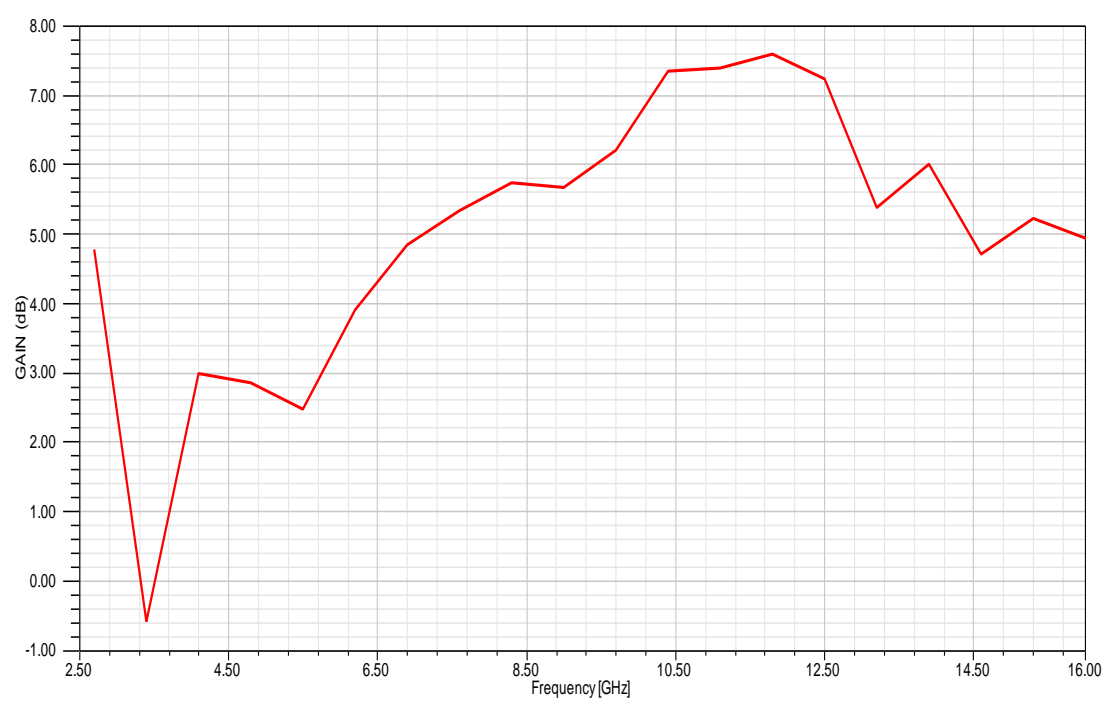

Fig.12. Gain versus frequency plot of proposed antenna with notch band WIMAX.

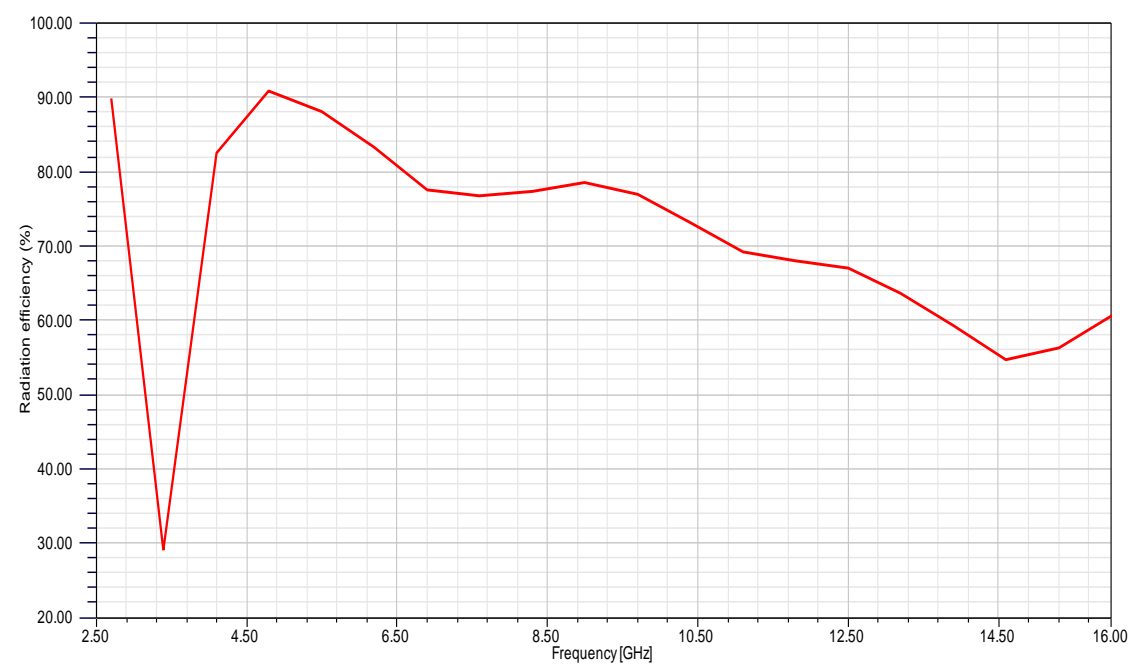

Fig.13. Radiation efficiency versus frequency plot of proposed antenna with notch band WIMAX.

The simulated antenna gain (Fig. 12), shows a gain decrement at approximately $3.4 \mathrm{GHz}$ and shifted $-0.5 \mathrm{~dB}$, which confirm the filtering effects. The simulated gain varies between 3 and $7.5 \mathrm{~dB}$ across 
the band of 4.1 to $12 \mathrm{GHz}$. The radiation efficiency of the antenna is shown in Fig. 13. The efficiency is higher than $68 \%$ between 3.9 and $12 \mathrm{GHz}$ and dropped to $30 \%$ at the notched frequency of $3.4 \mathrm{GHz}$.

\section{CONCLUSION}

A compact UWB CDR antenna integrated monopole with single band notched characteristics has been presented, which has a simple structure and satisfies the $S_{11}$ less than $-10 \mathrm{~dB}$ requirement for 3.3 to more than $12 \mathrm{GHz}$. The simulated data show that the proposed antenna can produce a relatively low frequency with reduced antenna radiation patch dimensions without the external matching network. We also observed that the bandwidth of the proposed monopole antenna is increased when associated with the CDR structure, providing an impedance bandwidth of more than $113 \%$. A U-shaped slot etched on the patch induces a band notch at the WIMAX frequency band $(3.2-3.8 \mathrm{GHz})$. The centre frequency of the notched band can be varied from 3.4 to $4.5 \mathrm{GHz}$ by changing the position of CDR. The notch frequency depends on the dimensions of the U-shaped slot as well as the CDR position. The simulated results for the antenna VSWR and radiation patterns were provided with the use of CST Microwave studio and were validated by using HFSS software. The slight difference between the simulated results is due to the different numerical techniques employed by the two softwares. The simplicity, compact size, low cost, and band rejection make this antenna suitable for UWB applications.

\section{REFERENCES}

[1] A. Petosa, "Dielectric Resonator Antenna Handbook," Norwood. A, USA: Artech House, 2007.

[2] T. A. Denidni, Q. Rao, and A. R. Sebak,"Broadband L-Shaped Dielectric Resonator Antenna,"IEEE Antennas and Wireless Propagation Letters, vol. 4, pp.453-454, 2005.

[3] W. Jiang and W. Q. Che, "A novel UWB antenna with dual notched bands for WIMAX and WLAN applications," IEEE Antennas and Wireless Propagation Letters, vol. 11, pp. 293-296,2012.

[4] P. V. Bijumon, S. K. Menon, M. N. Suma, B. Lehakumari, M. T.Sebastian, and P. Mohanan, "Broadband elliptical dielectric resonator antenna,"Microwave and Optical Technology Letters, vol. 48, no. 1, pp. 65-67, 2006.

[5] Q. Rao, T. A. Denidni, and A. R. Sebak, "Broadband compact stacked t-shaped DRA with equilateral-triangle cross sections,"IEEE Microwave and Wireless Components Letters, vol.16, no.1, pp. 7-9, 2006.

[6] R. Chair,A. A. Kishk, and K. F. Lee, "Wideband stair-shaped dielectric resonator antennas," IET Microwave, Antennas and Propagation, vol. 1, no. 2, pp. 299-305, 2007.

[7] S. M. Shum, and K. M. Luk, "Stacked annular-ring dielectric resonator antenna excited by axi-symmetric coaxial probe," IEEE Transactions on Antennas and Propagation, vol.43,no.8, pp. 889-892, 1995.

[8] A. A. Kishk, Yan. Yin, and A. W. Glisson, "Conical dielectric resonator antennas for wide-band applications," IEEE Transactions on Antennas and Propagation, vol.50, no.4, pp. 469-474, 2002.

[9] Z. Chen and H.Wong, "Wideband Glass and Liquid Cylindrical Dielectric Resonator Antenna for Pattern Reconfigurable Design,” IEEE Transactions on Antennas and Propagation, vol. 65, no.6, pp. 2157- 2164, 2017.

[10] A. G. Walsh, C. S. Deyoung, and S. A. Long, "An investigation of stacked and embedded cylindrical dielectric resonator antennas," IEEE Antennas and Wireless Propagation Letters, vol. 5, pp. 130-133, 2006.

[11] M.Y. Abou Shahine, M. Al-Husseini, K. Y. Kabalan , and A. El-Hajj, “ Dielectric Resonator Antennas with Band Rejection and Frequency Reconfigurability," Progress In Electromagnetics Research C, vol. 46, pp.101-108, 2014.

[12] T. A. Denidni and Z. Weng,"Hybrid ultrawideban dielectric resonator antenna and band notched designs," IET Microwaves, Antenna and Propagation, vol.5 , no.4 , pp.450- 458, 2011.

[13] T.H.Chang and J.F. Kiang, "Dualband split dielectric resonator antenna," IEEE Transactions on Antennas and Propagation, vol. 55, no. 11,pp. 3155-3162, 2007.

[14] K.S.Ryu and A.A. Kishk, "UWB antenna with single or dual band notches for lower WLAN band and upper WLAN band," IEEE Transactions on Antennas and Propagation .vol. 57, no.12, pp.3942-3950, 2009.

[15] A.Kerkhoff and H.Ling, "Design of a planar monopole antenna for use with ultra wideband (UWB) having a bandnotched characteristic," IEEE Antennas and propagation society International Symposium Digest, vol.1, pp.830-833, 2003. 
[16] W. J. Lui, C. H. Cheng, Y. Cheng, and H. Zhu, " Frequency notched ultra-wideband microstrip slot antenna with fractal tuning stub," Electronic Letters. vol.41, no.6, pp. 294-296, 2005.

[17] C. M. Li and L. H. Ye,"Improved dual band-notched uwb slot antenna with controllable notched band-widths," Progress in Electromagnetics Research, vol. 115, pp. 477-493, 2011.

[18] A. Syed and R. W. Aldhaheri, "A Very Compact and Low Profile UWB Planar Antenna with WLAN Band Rejection," The Scientific World Journal, Volume 2016, Article ID 3560938, 7 pages.

[19] W. S. Lee, D. Z. Kim, K.J.Kim, and J.W. Yu, "Wideband planar monopole antennas with dual band-notched characteristics," IEEE Transactions on Microwave Theory and Techniques, vol. 54, no. 6, pp. 2800-2806, 2006.

[20] R. Eshtiaghi, R. Zaker, J. Nouronia, and C. Ghobadi, "UWB semi-elliptical printed monopole antenna with subband rejection filter," International Journal of Electronic and Communications , vol. 64, no.2, pp.133-41, 2008.

[21] W. C. Liu and C. F. Hsu, "Dual-band CPW-fed Y-shaped monopole antenna for PCS/WLAN application," Electronic Letters, vol. 41, no. 17, pp. 390-391, 2005.

[22] N. D. Trang, D. H. Lee, and H. C. Park, "Compact printed CPW-fed monopole ultra-wideband antenna with triple subband notched characteristics," Electronic. Letters. vol. 46, no. 17, pp. 1177-1179, 2010.

[23] N. Ojaroudi, M. Ojaroudi, and N. Ghadimi, "Dual band notched small monopole antenna with novel W-shaped conductor backed-plane and novel T-shaped slot for UWB applications," IET Microwaves, Antennas and Propagation, vol. 7, no. 1, pp. 8-14, 2013.

[24] B. Li, J. Hong, and B. Wang, "Switched band-notched UWB/dual-band WLAN slot antenna with inverted S-shaped slots," IEEE Antennas and Wireless Propagation Letters, vol. 11, pp. 572-575, 2012.

[25] J.-Y. Deng, Y.-Z. Yin, Sh.-G. Zhou and Q.-Zh. Liu. "Compact ultra-wideband antenna with tri-band notched characteristic," Electronic Letters, vol. 44 , no.21, pp. 1231-1233, 2008.

[26] A. Valizade, C. Ghobadi, J. Nourinia, and M. Ojaroudi, "A novel design of reconfigurable slot antenna with switchable band notch and multiresonance functions for uwb applications," IEEE Antennas and Wireless Propagation Letters, vol. 11, pp.1166-1169, 2012.

[27] W.S. Lee, D.Z. Kim, K.J. Kim, and J.W.Yu, "Wideband Planar Monopole Antennas With Dual Band-Notched Characteristics," IEEE Transactions on Microwave Theory and Techniques, vol.54, no 6,pp.2800-2806, 2006. 